\title{
Mobilizando o pensamento geométrico em um grupo de estudos: o caso da professora Vanda
}

\section{Cirléia Pereira Barbosa}

Instituto Federal de Minas Gerais

cirleia.barbosa@ifmg.edu.br

\author{
Ana Cristina Ferreira \\ Universidade Federal de Ouro Preto \\ anacf@iceb.ufop.br
}

\section{Resumo}

O presente artigo apresenta um estudo de caso cujo foco é investigar a mobilização de saberes de uma professora que leciona Matemática nos anos iniciais do Ensino Fundamental, ao participar de um grupo de estudos voltado para o desenvolvimento do pensamento geométrico. Os dados foram coletados por meio de diagnósticos de conhecimentos geométricos, registros produzidos pela professora, diário de campo da pesquisadora, uma entrevista e gravações em áudio e/ou vídeo dos encontros. Os resultados evidenciam o desenvolvimento do pensamento geométrico da professora, expresso não apenas pelo aprimoramento da linguagem utilizada, mas, principalmente, pelos registros produzidos por ela.

Palavras-chave: Educação Matemática. Pensamento Geométrico. Desenvolvimento Profissional. Anos iniciais do Ensino Fundamental.

\section{Mobilizing the geometrical thinking in a group of studies: the case of teacher Vanda}

\begin{abstract}
This article presents a case study whose focus is to investigate the mobilization of knowledge from a teacher who teaches mathematics in the early years of elementary school, to participate in a study group focused on the development of geometrical thinking. Data were collected through diagnoses of geometrical knowledge, records produced by the teacher, researcher's field diary, an interview and audio recordings and/or video meetings. The results show the development of the geometrical thinking of teacher, expressed not only by the improvement of the language used, but mainly by the records produced by it.
\end{abstract}

Keywords: Mathematics Education. Geometrical Thinking. Professional Development. Teachers. Early years of elementary school. 


\section{Introdução}

Este texto apresenta um recorte de uma pesquisa de Mestrado cujo propósito era investigar a mobilização do pensamento geométrico de professores que lecionam Matemática nos anos iniciais do Ensino Fundamental de uma escola pública de Ouro Preto (MG), ao participarem de um grupo de estudos, constituído de três professoras que lecionam Matemática nos anos iniciais do Ensino Fundamental de Ouro Preto (MG) e as pesquisadoras. Na Dissertação construída a partir dessa pesquisa, analisamos quatro estudos de caso - um de cada professora e um do grupo.

O principal objetivo deste artigo é evidenciar a mobilização de saberes ${ }^{1}$, em especial, aqueles relacionados ao pensamento geométrico, por uma das professoras do grupo, ao longo de sua participação no grupo de estudos.

\section{O desenvolvimento do pensamento geométrico}

O presente estudo se fundamentou, basicamente, em Pais (1996), Gutierrez (1996), Passos (2000) e Nacarato (2005) para compreender o desenvolvimento do pensamento geométrico. Essa escolha se deu pela proximidade entre as ideias dos autores e pelo suporte que proporcionaram à análise dos dados.

Pais (1996) propõe quatro elementos fundamentais no processo de representação plana de um objeto tridimensional: objeto, desenho, imagem mental e conceito. O termo objeto é interpretado pelo autor como parte material, palpável do mundo real e que pode ser associada à forma de alguns conceitos geométricos. Assim, o objeto associado ao conceito de cubo pode ser uma representação desse sólido construída com varetas, cartolina, argila ou qualquer outro material. Segundo o autor, o objeto é entendido como forma primitiva de representar conceitos, uma vez que o processo de construção teórica é lento, gradual e complexo. Nesse sentido, o objeto é um modelo físico que contribui para a formulação de ideias, mas não as substitui.

Em nosso estudo, utilizamos o termo objeto "apenas em sua acepção concreta" (PAIS, 1996, p. 66), como sinônimo de 'material concreto', 'material manuseável' ou 'material manipulativo', no sentido atribuído por Nacarato (2005).

Da mesma maneira que o objeto, o desenho também é de natureza concreta e, portanto, não apresenta características abstratas e gerais do conceito. Pais (1996) destaca que o uso do desenho na geometria plana é mais simples do que na geometria espacial, onde o uso de perspectivas torna-se uma das maiores dificuldades enfrentadas pelos alunos na aprendizagem dos conceitos geométricos. 
A nosso ver, os quatro elementos fundamentais no processo de representação plana de um objeto tridimensional, destacados por Pais (1996), parecem-nos ajudar a analisar o pensamento geométrico manifestado por professores nesse sentido. Entretanto, torna-se necessário aprofundar nosso conhecimento acerca do pensamento geométrico e ampliá-lo de modo a incluir esses elementos discutidos acima e compreender melhor sua relação com o desenvolvimento do pensamento geométrico.

Em nossa pesquisa, entendemos que conceitos expressam ideias e representações gerais (FISCHBEIN, 1993) e constituem o conhecimento teórico da Geometria (PAIS, 1996) e, imagens mentais são representações internas de um conceito ou propriedade, reveladas por meio de elementos verbais ou visuais - gráficos, desenhos, linhas, etc. (YAKIMANSKAYA, 1991 apud GUTIERREZ, 1996).

Em relação às figuras geométricas, Fischbein (1993) destaca algumas características relacionadas à sua natureza conceitual. Em primeiro lugar, deve-se observar que no raciocínio matemático os objetos materiais (sólidos ou desenhos) são modelos materializados de entidades mentais. Sendo assim, os elementos de um objeto geométrico (lados, vértices, ângulos) não são considerados objetos materiais ou desenhos. Em segundo lugar, somente em um sentido conceitual podem-se considerar as entidades geométricas: linhas, retas, círculos, quadrados, triângulos, cubos, etc. Em terceiro lugar destaca que pontos (objetos de dimensão zero), linhas (objetos unidimensionais), planos, (objetos bidimensionais) não existem na realidade empírica. Apenas os objetos reais são necessariamente tridimensionais. Em quarto lugar, ressalta que tanto as construções geométricas quanto o conceito são representações gerais e não cópias mentais de objetos concretos. Por exemplo, quando se desenha um triângulo $\mathrm{ABC}$ em uma folha de papel com o objetivo de conferir algumas de suas propriedades, como o fato das alturas serem concorrentes, não se faz referência apenas a este triângulo, mas a uma infinidade de triângulos que gozam as mesmas propriedades.

Por último, destaca uma característica das figuras geométricas relacionada à sua natureza conceitual, ou seja, o fato de as propriedades das figuras geométricas partirem de definições vindas de um sistema axiomático. Como exemplo, ele explica que:

[...] um quadrado não é uma imagem desenhada numa folha de papel. É uma forma controlada por sua definição (embora possa ser inspirada por um objeto real). Um quadrado é um retângulo que tem lados iguais. Partindo dessas propriedades pode-se prosseguir descobrindo outras propriedades 
do quadrado (a igualdade de ângulos, que são todos retos, a igualdade das diagonais, etc. (FISCHBEIN, 1993, p.1412)

Portanto, segundo o autor, uma figura geométrica não é um mero conceito propriamente dito, mas possui intrinsecamente a ela, propriedades conceituais. Para ele, uma figura geométrica é uma imagem visual, que goza de uma propriedade que conceitos usuais não a têm, ou seja, a representação mental do espaço.

Assim, os objetos empíricos no pensamento geométrico são entidades mentais denominadas conceitos figurais, que possuem ao mesmo tempo propriedades espaciais (formas, posição, magnitude) e conceituais. Segundo Fischbein (1993), a figura geométrica é uma imagem mental cujas propriedades são controladas por definição. O desenho não é, em si, uma figura geométrica propriamente dita, mas uma espécie de gráfico dessa figura. E, a imagem mental de uma figura geométrica é a representação do modelo materializado da figura.

A visualização e a representação são outros dois elementos (indissociáveis) importantes para a formação do pensamento geométrico. Para Gutiérrez (1996, p. 9) a visualização em Matemática é "um tipo de raciocínio baseado no uso de elementos visuais e espaciais, tanto mentais quanto físicos, desenvolvidos para resolver problemas ou provar propriedades". A visualização integra-se a quatro elementos principais: imagens mentais, representações externas, processos de visualização e habilidades de visualização ${ }^{3}$.

Nossa prática enquanto professora e formadora tem nos mostrado a dificuldade de compreensão que algumas pessoas apresentam nas transformações sofridas por um objeto tridimensional para o bidimensional e vice-versa. Muitas vezes, essa dificuldade pode estar na identificação dos diferentes elementos que compõem esses objetos. Dessa forma, elas não conseguem representar determinadas propriedades desses objetos, em decorrência da deficiência ou ausência do ensino de Geometria.

2. "A square is not an image drawn on a sheet of paper. It is a shape controlled by its definition (though it may be inspired by a real object). A square is a rectangle having equal sides. Starting from these properties one may go on for discovering other properties of the square (the equality of angles which are all right angles, the equality of diagonals, etc.)".

3. De acordo com esse autor: [...] uma imagem mental é qualquer tipo de representação cognitiva de um conceito matemático ou propriedade, por meio de elementos visuais ou espaciais; [...] uma representação externa pertinente à visualização é qualquer tipo de representação gráfica ou verbal de conceitos ou propriedades incluindo figuras, desenhos, diagramas, etc, que ajudam a criar ou transformar imagens mentais e produzir raciocínio visual; [...] um processo de visualização é uma ação física ou mental, onde imagens mentais estão envolvidas. Existem dois processos realizados na visualização: a "interpretação visual de informações" para criar imagens mentais e a "interpretação de imagens mentais" para gerar informações (p.9-10). 
Em nossa pesquisa, o ensino e a aprendizagem da Geometria são elementos fundamentais. Nesse sentido, propusemos a criação de um grupo de estudos, envolvendo pesquisadores e professores dos anos iniciais do Ensino Fundamental, visando contribuir para o desenvolvimento dos saberes profissionais ${ }^{4}$ e, em especial, para o desenvolvimento do pensamento geométrico de todos os envolvidos. No recorte feito para este artigo, analisaremos a mobilização do pensamento geométrico de uma das participantes do grupo.

\section{Metodologia e procedimentos metodológicos}

A pesquisa, de cunho qualitativo, buscou responder à seguinte questão: Que saberes são mobilizados por professores que lecionam Matemática nos anos iniciais do Ensino Fundamental de uma escola pública de Ouro Preto (MG), ao participarem de um grupo de estudos com foco no pensamento geométrico?

Para isso, constituímos um grupo de estudos formado por três professoras ${ }^{5}$ que lecionavam Matemática nos anos iniciais do Ensino Fundamental e as pesquisadoras. Foram 24 horas de atividades distribuídas em 16 encontros semanais (às terças-feiras), em horário extraclasse, de fevereiro a junho de 2010.

Os instrumentos de coleta de dados foram: diário de campo da pesquisadora, registros escritos das professoras participantes, gravações em áudio e/ou vídeo dos encontros, uma entrevista, realizada ao longo do trabalho, e dois diagnósticos de conhecimentos geométricos (inicial e final). O primeiro tinha o objetivo de proporcionar uma referência inicial acerca dos conhecimentos geométricos das participantes, e o segundo se propunha a identificar saberes mobilizados (ou não) pelo trabalho, em especial, relacionados ao pensamento geométrico.

A dinâmica dos encontros norteou-se pelo referencial teórico e por nossas concepções sobre ensino de Geometria (centrado na ação dos participantes), bem como nossa preocupação com a formação docente. Assim, procuramos desenvolver atividades a partir de materiais manipulativos (argila, espelhos, palitos, cartolina, jogos, geoplano, etc.) e promover discussões acerca da utilização dessas tarefas em

4. Entendemos saberes profissionais (ou docentes) como um conjunto de conhecimentos oriundos de diversas fontes (formação escolar, formação inicial e continuada, currículo, conhecimentos de disciplinas a serem ensinadas, experiência profissional, identidade pessoal, etc.). Esses saberes são característicos da prática docente e sofrem influência da história de vida pessoal e profissional do professor, como experiências anteriores, aprendizagem com seus pares, interações com seus alunos na sala de aula, dentre outros.

5. O convite para participar do grupo de estudos foi feito a todos os professores dos anos iniciais do Ensino Fundamental da escola. Inicialmente, cinco professores manifestaram interesse em participar. Porém, após os primeiros encontros, duas professoras, devido a motivos pessoais, não puderam continuar no grupo de estudos. 
sala de aula, bem como a troca de experiências e criação de materiais/atividades pelas participantes.

A análise realizou-se por meio de estudos de casos. Para construir cada caso, utilizamos a triangulação de dados. Além disso, retomamos todo o material organizado e a literatura referente ao pensamento geométrico, procurando, em cada atividade, analisar os saberes mobilizados (ou não) de cada professora. O caminho escolhido privilegiou três categorias - uso adequado de termos geométricos, visualização e representação, e compreensão de conceitos - que emergiram, tanto dos dados, quanto de nossas discussões, e leituras iniciais que nortearam a construção das atividades desenvolvidas nos encontros.

Dessa forma, ao todo, realizamos quatro estudos de caso: um estudo de cada professora e um estudo do grupo. As unidades de análise foram as professoras e o grupo. No presente artigo, apresentamos o caso da professora Vanda ${ }^{6}$.

\section{Um pouco da história de Vanda}

Vanda é professora há cerca de 20 anos. Começou sua experiência docente na Educação Infantil. Após concluir o antigo curso de Magistério, cursou a Licenciatura Básica para os anos iniciais do Ensino Fundamental, modalidade a distância, em uma universidade pública. No ano de 2010, era vice-diretora da escola.

Quando perguntada acerca de sua relação com a Geometria, a professora afirmou que estudou pouco Geometria ao longo da Educação Básica e que, na formação inicial, recorda-se de ter tido contato com conteúdos como sólidos geométricos, área e perímetro de figuras, mas de modo predominantemente teórico. Ainda na graduação, começou a participar de cursos de formação continuada para professores dos anos iniciais. Por isso, não teve dificuldade nos conteúdos geométricos durante a Licenciatura.

Em sua experiência profissional, quando não ocupava cargos na administração escolar, sempre procurava trabalhar com a Geometria em sala de aula. Costumava desenvolver atividades sobre planificações (montagem de superfícies) e identificação de elementos de poliedros utilizando embalagens.

Para Vanda, as crianças não apresentam dificuldade em aprender Geometria, mas sim os professores que, em geral, priorizam as operações fundamentais e dão pouca importância aos conteúdos geométricos. Segundo ela, esse fato se relaciona

6. Considerando as limitações de espaço e visando tratar de modo aprofundado o processo vivido no grupo, optamos por apresentar neste artigo apenas o caso de uma professora. A escolha de Vanda foi realizada aleatoriamente. O caso de Marta encontra-se no prelo e pretendemos explorar futuramente o caso de Andréa. 
à formação dos docentes: "acho que talvez pelo jeito que foi passado pra eles. A gente foi acostumada com as quatro operações. Matemática era quatro operações e problemas. Então Geometria usava-se como arte, aula de arte, desenho artístico" (entrevista, 06/04/10).

Participante assídua, Vanda desempenhou o papel de interlocutora do grupo, pois indagava e instigava as colegas a (re)pensarem acerca de conceitos geométricos.

\section{Analisando a mobilização de saberes da professora}

A seguir, analisamos os saberes relacionados ao pensamento geométrico, mobilizados por Vanda ao longo dos encontros com o grupo, tendo em vista as categorias: uso adequado de termos geométricos, visualização e representação, e compreensão de conceitos.

\section{Uso adequado de termos geométricos}

Desde o início dos encontros com o grupo, Vanda demonstrou espontaneidade para se expressar. Em vários momentos, era ela quem desencadeava as discussões acerca do desenvolvimento das atividades propostas. Ao longo do processo, percebemos que ela trazia em seu discurso o uso adequado de termos geométricos, ou seja, um vocabulário que continha a nomenclatura das formas e termos específicos.

Essa figura de lados oblíquos (referindo-se ao paralelogramo), como é mesmo o nome dela? Trapézio? [...] Retângulo? Ah! Sei... Como é mesmo o nome? Não é perpendicular (Notas de campo, 06/04/10).

Elas têm a mesma medida. É... mesma distância ( $8^{\circ}$ encontro, 04/05/10).

Se aqui tem seis, se o hexágono tem seis, o octógono tem oito $\left(11^{\circ}\right.$ encontro, 25/05/10).

O meu (refere-se a um triângulo) é isósceles e obtusângulo (14 encontro, $15 / 06 / 10)$.

As expressões destacadas nas falas anteriores ilustram o uso adequado de termos geométricos. Podemos observar que Vanda mencionou tanto o nome de algumas figuras, quanto termos particulares da Geometria, por exemplo, oblíquos, perpendicular, mesma medida.

No início do processo, ela se referia ao paralelogramo como 'figura de lados oblíquos'. A partir do $10^{\circ}$ encontro, notamos um uso mais apropriado: "Possui dois pares de lados paralelos" (notas de campo, 18/05/10). Tais situações evidenciam uma mobilização de saberes relacionados ao uso adequado de termos geométricos. 
Mobilizando o pensamento geométrico em um grupo de estudos: o caso da professora Vanda

Outros exemplos reforçam essa ideia. A seguir, apresentamos a produção da professora em duas atividades - uma desenvolvida no $15^{\circ}$ encontro e outra no diagnóstico final - com o mesmo propósito: interpretar gráficos e escrever um itinerário usando vocabulário adequado, por exemplo, esquerda e direita.

no tercuiro quadradimbo da socé inicia subindo para o terceiro quadrado do 2 - limbo, vine a dineita, suba $l$ pire a esquerch ati o $2:$ quadrob suba 4 quadrados, pire a direita desca.

(a) Primeira resolução $\left(15^{\circ}\right.$ encontro, 22/06/10)

1 passo a jente, vine - esquerda e dì, 2 passos, vire a direita e di 2 passos, vine a direita dé un passo vive a diserta e dis 2 passos, vive a esquesda e de 2 passos evire a dinceita e dê I passo.

(b) Segunda resolução (diagnóstico final, 29/06/10)

Figura 1. Fotos do caderno e do diagnóstico final da professora Vanda

Na figura 1 (a), os termos destacados evidenciam o uso inadequado de termos, como 'subir' e 'descer'. A figura 1(b), do diagnóstico final, sugere um aprimoramento da linguagem, com a utilização de termos mais apropriados relacionados às noções espaciais, como 'vire à direita' ou 'vire à esquerda' e caminhe certa quantidade de passos.

BOLETIM GEPEM (pISSN: 0104-9739, eISSN: 2176-2988) ｜Ｎo 62-JAN. / JUL. $2013 \quad 62$ 


\section{Visualização e representação}

Uma breve análise do primeiro diagnóstico indicou alguns saberes manifestados pela professora, em especial, os saberes do conteúdo. O objetivo da primeira questão era reconhecer que quadrados e losangos apresentam quatro lados de mesma medida. Tratava-se, portanto, de uma questão de discriminação visual, uma das habilidades definidas por Gutiérrez (1996). A figura a seguir ilustra a resolução da professora.

1) Ao escolher lajotas para o piso de sua varanda, Lona Lúcia falou ao vendedor que precisava de lajotas que tivessem os quatro lados com a mesma medida.
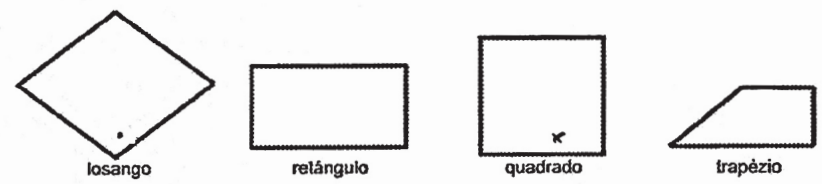

Que lajotas o vendedor deve mostrar a Dona Lúcia? Explique sua resposta.

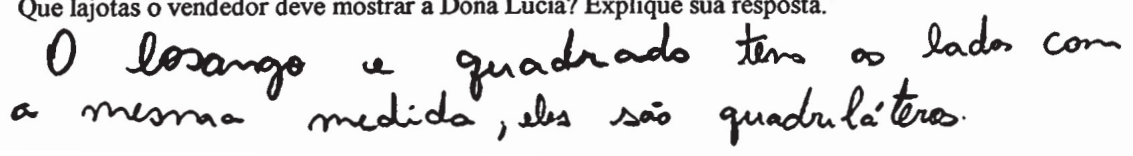

Figura 2. Resolução da primeira questão do diagnóstico inicial ( $2^{\circ}$ encontro, 23/03/10)

Vanda respondeu corretamente à questão, destacando inclusive que tais figuras eram quadriláteros.

Outra questão possuía duplo objetivo: relacionar o objeto (latinha de refrigerante) ao seu conceito (cilindro) e desenho (planificação), e analisar como cada participante, como professora da turma, atuaria na situação dada. Vejamos como Vanda respondeu:

\section{En trabalharia antes,}

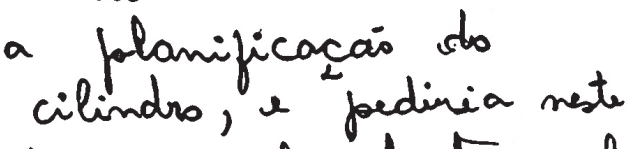
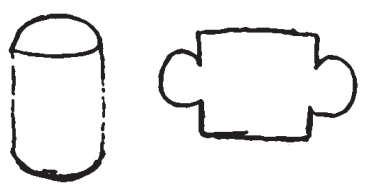
mimento para desentran atranís delo.

Figura 3. Resolução da quinta questão do diagnóstico inicial ( $2^{\circ}$ encontro, $\left.23 / 03 / 10\right)$ 
O registro de Vanda evidencia sua habilidade de visualização e representação do objeto, embora o desenho não represente corretamente a planificação do modelo (cilindro). Ao associar a latinha de refrigerante ao cilindro e à sua planificação, ela formou as imagens mentais do objeto e o representou através do desenho, um tipo de representação externa à visualização (GUTIÉRREZ, 1996).

De modo geral, o diagnóstico inicial evidenciou que Vanda era capaz de comparar quadriláteros e identificar semelhanças e diferenças entre eles, identificar figuras específicas em diferentes objetos e de associar o objeto cubo à sua planificação, bem como alguns saberes relacionados ao conteúdo.

Nos encontros seguintes, planejamos a criação de um modelo de embalagem. Para isso, com antecedência, propusemos ao grupo a tarefa de modelar sólidos geométricos, usando argila, e representar três diferentes perspectivas de um mesmo objeto (vista superior, vista frontal e vista lateral).

Vanda modelou duas pirâmides (uma triangular e outra pentagonal), dois prismas (um retangular e outro triangular), um cone, um cilindro e uma esfera. Para representar diferentes vistas, ela escolheu a pirâmide triangular e o cilindro.
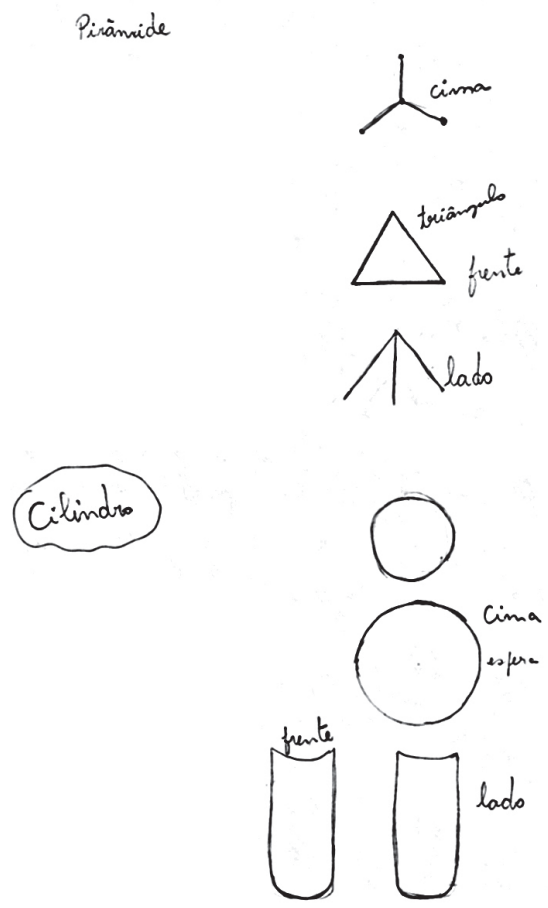

Figura 4. Perspectivas $\left(6^{\circ}\right.$ encontro, 20/04/10) 
Para representar a vista superior da pirâmide triangular, a professora desenhou três segmentos concorrentes, os quais denominou 'tracinhos', e destacou os pontos. Em outra perspectiva (vista lateral), ela identificou dois triângulos, mas não representou o terceiro lado dessas figuras. Em relação ao cilindro, ela representou corretamente a vista superior, porém, nomeou a figura como esfera, em vez de círculo.

No $7^{\circ}$ encontro, em uma tarefa envolvendo a visualização e a representação, observamos a dificuldade da professora em representar as bases paralelas de uma caixa. Sua dúvida era saber a qual dos retângulos (faces laterais) cada base estava vinculada. A figura seguinte mostra o projeto de embalagem criado pela professora e algumas perspectivas do objeto representadas por ela.

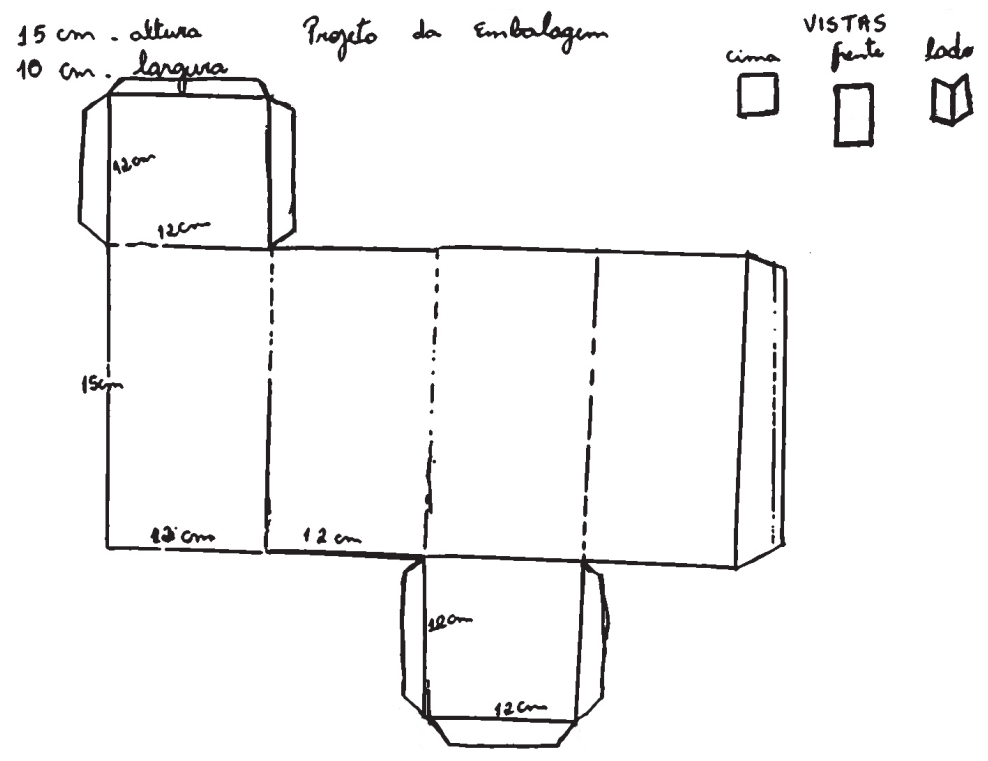

Figura 5. Projeto do modelo de embalagem ( $7^{\circ}$ encontro, 27/04/10)

Além da planificação do modelo de embalagem, Vanda também representou três diferentes perspectivas do objeto (superior, frontal e lateral), antes de montá-lo. A representação feita por ela evidenciou sua habilidade de constância perceptual uma das habilidades visuais definidas por Gutiérrez (1996).

Contudo, a dificuldade apresentada pela professora ao planificar modelos da embalagem não apareceu no diagnóstico final. A figura a seguir ilustra a planificação feita por Vanda. 

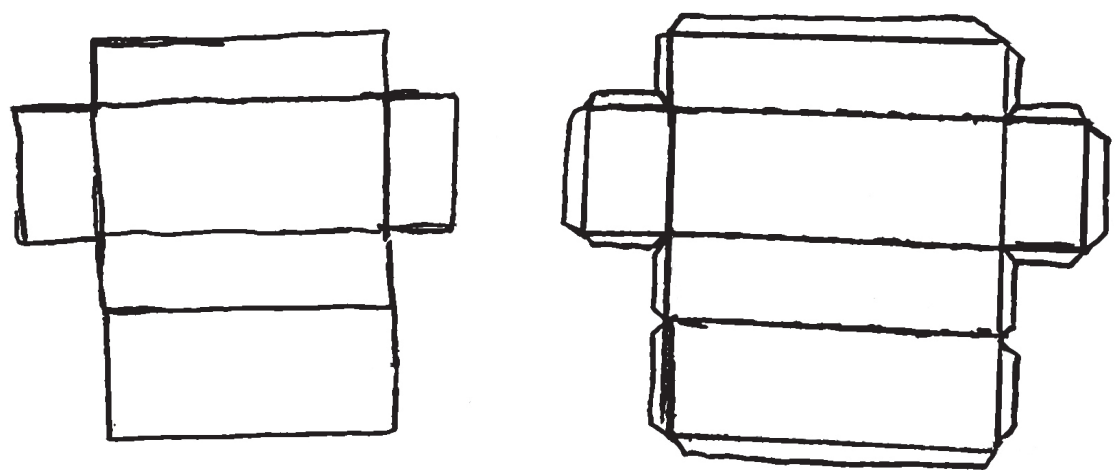

Figura 6. Resolução da segunda questão do diagnóstico final (Vanda, 29/06/10)

A professora fez duas planificações. Na primeira, representou todas as faces. É possível notar sua preocupação em mostrar que os retângulos têm diferentes dimensões. Na segunda representação, ela destacou os encaixes (pequenas abas) para montar a caixa. Analisando ambas as representações, percebemos que, embora as formas não sejam proporcionais ao tamanho da caixa, ela manteve o número de elementos, representando inclusive as bases paralelas da superfície do prisma.

\section{Compreensão de conceitos}

No terceiro encontro, trouxemos para o grupo algumas atividades com embalagens. A proposta era separar os objetos em grupos, de acordo com um critério definido. A seguir, apresentamos um dos episódios:

Pesquisadora: Agora tenta fazer o contorno da mesma lateral que você fez. Agora pra essa embalagem (referindo-me à lata de refrigerante).

Marta: Vai ficar quadrado! (ri)

Vanda: Vai ficar quadrado? E essa forma circular aí? (Referindo-se à base da lata.)

Vanda: Mas aí você não tá fazendo o contorno dela toda não. (Após Marta terminar o desenho.)

Marta: É... Não tô fazendo o contorno dela todo não. (Olha para mim com expressão de dúvida.)

Vanda: Ela não faz o contorno. Por quê? (Mexe a cabeça no sentido negativo e olha para Marta.)

Pesquisadora: O que está acontecendo quando você vai fazer o contorno? Vanda: Como ela rola ... ela não deixa.

Pesquisadora: E essa embalagem então: tem face ou não tem face? 
Marta: Não tem!

Vanda: Não tem não. (confirma)

Marta: É a mesma coisa que falasse que não tem lado? Ela não tem lado.

Vanda: Como ela é forma redonda ela não tem lado porque a forma redonda anda.

Marta: Eu posso falar que ela tem a frente? (Mostra a vista frontal da lata de refrigerante.)

Vanda: Não! Não tem frente não! Tem frente aí Marta? Olha do outro lado. ( $3^{\circ}$ encontro, $\left.30 / 03 / 10\right)$

Algumas falas acima sugerem o desenvolvimento do pensamento geométrico, por exemplo, quando Vanda questiona a colega sobre o contorno da base: "Vai ficar quadrado? E essa forma circular ai?". Nesse momento, ela cria imagens mentais para gerar informações (GUTIÉRREZ, 1996). E conclui que, se a embalagem 'rola', então não tem faces.

No $11^{\circ}$ encontro, propusemos uma atividade em que o grupo discutia o conceito de retângulo e quadrado, através de construções geométricas. Uma das tarefas era construir um retângulo, cujos lados medissem seis centímetros. O trecho seguinte traz falas de Vanda.

Eh, então vai fazer um quadrado, né! Praticamente... pelos os lados serem iguais, né? [...] O quadrilátero que possui quatro ângulos retos. O quadrado possui 4 ângulos retos! (pausa) As medidas aí são iguais... [...] É retângulo! É um quadrilátero com quatro ângulos retos![...] Quadrado e retângulo são paralelogramos. Quadrado: quatro lados iguais ( $11^{\circ}$ encontro, 25/05/10).

Podemos observar que ela associou as informações dadas (construir um retângulo de lados $6 \mathrm{~cm}$ ) à construção de um quadrado. Isso sugere que a professora criou as imagens mentais da figura, controladas pela própria definição (quadrilátero que possui quatro ângulos retos e quatro lados de mesma medida), e demonstrou compreensão do conceito de quadrado, destacando inclusive suas propriedades conceituais.

\section{Considerações Finais}

Nesse estudo de caso, buscamos analisar saberes mobilizados (ou não) relacionados ao uso adequado de termos geométricos, à visualização e representação, e à compreensão de conceitos. 
Em relação ao uso adequado de termos geométricos, percebemos em alguns trechos que a professora demonstrou o conhecimento de propriedades de figuras ou de orientação espacial, contudo, não utilizava termos apropriados. A forma como cada professor se expressa em sala de aula, especialmente no ensino da Geometria, pode conduzir os alunos à compreensão errônea de conceitos. Daí a importância de aprimorar essa habilidade a partir do aprofundamento dos conhecimentos.

A visualização e a representação desempenham um papel fundamental na construção do pensamento geométrico e, consequentemente, na compreensão dos conceitos. Em nosso grupo, buscamos desenvolver atividades com materiais manipulativos visando a criação das imagens mentais (PAIS, 1996, 2000; NACARATO, 2005); e, ao mesmo tempo, incentivávamos o registro escrito como auxiliar na formalização dos conceitos. Ao longo dos encontros, nos momentos em que Vanda resolvia e discutia as propostas no grupo, observamos o desenvolvimento dessas habilidades.

O estudo nos permitiu verificar que, como sugerem Fischbein (1993) e Nacarato e Passos (2003) contemplar o trabalho simultâneo entre o objeto, o conceito e o desenho, destacando os aspectos figurais e conceituais das figuras geométricas, pode contribuir de modo expressivo para o desenvolvimento do pensamento geométrico.

Por outro lado, também evidenciamos que a natureza das tarefas foi potencializada pelo trabalho coletivo. Ou seja, acreditamos que tais atividades não teriam o mesmo impacto se realizadas individualmente. Em vários momentos, ao longo do processo, presenciamos diálogos e trocas entre as professoras durante as discussões das atividades. Nas palavras da professora:

O Projeto de Geometria foi muito significativo, além de prazeroso. Tive a oportunidade de aprender geometria de forma bem elaborada, organizada e prática. A todo momento me sentia como uma aluna incentivada a aprender. [...] fiquei mais segura para ensinar meus alunos (Vanda, avaliação escrita, 29/06/10).

Mudou praticamente tudo. Eu já tô doida pra voltar pra sala de aula e colocar tudo o que a gente aprendeu ali. Desde o início, eu já havia falado que gostava muito de Geometria e continuo adorando cada vez mais. [...] O que eu mais espero é voltar pra sala de aula e aplicar o que a gente trabalhou. Foi ótimo! [...] O crescimento foi muito grande. Eu aprendi muita coisa. Noções que eu não tinha e que aprendi. Guardo o meu material lá diretinho pra quando eu voltar aplicar em sala de aula (Vanda, entrevista realizada alguns meses após o término do projeto, 17/05/11). 
Em síntese, essa experiência mostrou que a participação voluntária, a reflexão, o diálogo, o afeto e o estudo de conteúdos geométricos, centrados na aprendizagem e na prática, foram essenciais no processo vivido pelas professoras. No entanto, é importante esclarecer que a riqueza do grupo consiste na participação voluntária de seus membros que, de alguma maneira, se sentem insatisfeitos com seus saberes e/ ou práticas e desejam modificá-los.

\section{Referências}

FISCHBEIN, E.. The theory of figural concepts. EducationaI Studies in Mathematics. 24: 139-162, 1993.

GUTIERREZ, A. Visualization in 3-Dimensional Geometry: In Search of a Framework. University of Valence, Spain, 1996. Disponível em: <http://www.uv.es/ Angel.Gutierrez/archivos1/textospdf/Gut96c.pdf>. Acesso: fev. 2011.

NACARATO, A. M. Eu Trabalho Primeiro no Concreto. Revista de Educação Matemática, São Paulo, v. 9, n. 9-10, p. 1-6, 2005. SBEM-SP.

PAIS, L. C. Intuição, Experiência e Teoria Geométrica. Zetetiké, Campinas, SP, v. 4, n. 6, p. 65-74, jul./dez. 1996.

. Uma análise do significado da utilização de recursos didáticos no ensino da Geometria. In: ANPED, $23^{\mathrm{a}}$ reunião, 2000, Caxambu. Anais eletrônicos... Caxambu, 2000. Disponível em: <http://anped.org.br/23/textos/1919t.pdf>. Acesso: mar. 2010.

PASSOS, C. L. B. Representações, interpretações e prática pedagógica: a Geometria na sala de aula. Tese (Doutorado em Educação) - UNICAMP, Campinas, 2000.

Submetido em outubro de 2012 Aprovado em janeiro de 2013 